\title{
EFFECT OF AGING ON THE FLEXURAL STRENGTH OF TRANSLUCENT MONOLITHIC YTTRIA STABILIZED ZIRCONIA
}

\author{
Maha Adly Abd El Moaty*and Mohamed Mohey Eldien **
}

\begin{abstract}
Aim: the purpose of the present study was to investigate the effect of thermal cycling and mechanical loading on the flexural strength of: Zeno Star $(\mathrm{T})$ a translucent monolithic Yttria stabilized zirconia (Y-TZP).

Materials and Methods: a total number of 40 fully sintered bar - shaped specimens (18mm x $4 \mathrm{~mm} \times 1.2 \mathrm{~mm})$ were fabricated. The specimens were divided into 4 groups $(\mathrm{n}=10)$ according to the aging time: Group I: is the control group with no aging procedures and was tested after 24 hours. Group II: was subjected to thermal cycling (600 cycles) and load cycling 120.000 cycles equivalent to 6 months of clinical service. Group III: subjected to thermal cycling (1200 cycles) and load cycling 240.000 cycles equivalent to 1 year of clinical service. Group IV: subjected to thermal cycling 6000 thermal cycles and load cycles ( 1.200 .000 cycles) equivalent to 5 years of clinical service. For thermal cycling, all specimens were transferred in hot and cold water baths between 5 and $55^{\circ} \mathrm{C}$ in one minute cycle for each bath with dwell time of 30 seconds. The flexural strength was determined by three points bending test in a universal testing machine at a cross head speed of $1 \mathrm{~mm} /$ min. Tertragonal to monoclinic transformations due to thermal cycling and mechanical loading (LTD) was identified with X-ray diffraction (XRD).
\end{abstract}

Results: Comparing the flexural strength of the tested specimens, the mean flexural strength of zirconia in group II (representing six months of clinical service) was significantly higher $(1563.7 \pm 103.8$ MPa) than that of the control (group I) (1009.7 $\pm 107.2 \mathrm{MPa})$ Thermal cycling and mechanical loading equivalent to one year of clinical service (group III) led to significant decrease in the flexural strength $(1381 \pm 295 \mathrm{MPa})$ The lowest flexural strength was determined in group IV $(833.7 \pm 15.2 \mathrm{MPa})$ where zirconia was subjected to thermal cycling and mechanical loading equivalent to 5 years of clinical service. The relative XRD peak intensity showed that there were some monoclinic transformations at the end of the aging period which is equivalent to 5 years of clinical service.

Conclusions: Thermal cycling and mechanical loading caused a reduction in the mean flexural strength at the period equivalent to one year of clinical service. Further decrease of the flexural strength occurred following aging at the period simulating 5 years of clinical service with some phase transformation from tetragonal to monoclinic.

* Assistant Professor of Dental Biomaterials, Faculty of Dentistry, Alexandria University.

** Lecturer of Fixed Prosthodontics, Faculty of Dentistry, Delta University for Science and Technology. 


\section{INTRODUCTION}

All ceramic restorations are attractive in dentistry due to their esthetics and bio-compatibility. Interest in using high strength yttria-stabilized polycrystalline tetragonal zirconia (Y-TZP) ceramics for dental restorations has grown in recent years due to its high mechanical properties and manufacturing convenience using CAD/CAM procedures. ${ }^{(1)}$

Due to its relative opacity and high strength zirconia is used as a core material on which veneering porcelain is applied to enhance esthetics quality. In clinical service, the most frequent failure is the chipping of the veneer, while the high strength zirconia substructure is mostly not affected. ${ }^{(2)}$ New technologies allow for the creation of anatomically designed monolithic restorations. Optical appearance of opaque zirconia might be improved by modification in the fabrication and sintering process which were shown to increase translucency. (3) Yttria (3\%) is added to stabilize the crystal structure transformation during firing at an elevated temperature and to improve the physical properties of zirconia. The characteristic phase transformation from the tetragonal to monoclinic is known to be of the martensitic type. It is characterized by a transformation without mass transfer in a certain range of temperatures and changes in the shape of nucleus. Phase transformations are reversible and involve expansion of the core volume by 3 to $4 \% .^{(4)}$ This positive change in volume can cause closure of surface microcracks restricting them to propagate into the bulk of the material. However, severe transformation to monoclinic phase could generate stresses that cause surface uplifts and fragmentation of the material. ${ }^{(5,6)}$ The main problem associated with Y-TZP zirconia ceramics is their sensitivity to low temperature degradation (LTD).

Low temperature degradation is defined as hydrothermally induced spontaneous $t-m$ transformation occurring over time at low temperatures, when $\mathrm{t}-\mathrm{m}$ transformation is not triggered by the local stress produced at the tip of an advancing crack. With LTD, water constituents are incorporated into zirconia lattice leading to reduction in energy barrier for $\mathrm{t}-\mathrm{m}$ transformation. (7) Flexural strength is an important mechanical property to predict the performance of a material. It is the first parameter to be assessed to understand the clinical potential and limitations of a dental ceramic and is strongly affected by the defects and flaws present in the material. The forces applied on materials in the oral cavity develop cyclic loads that can be simulated by mechanical cycling which tends to be close to the physiological conditions generated by the chewing cycle. ${ }^{(8)}$

Recent studies demonstrated a reduced flexural strength of Y-TZPzirconia dependent on the extent and the depth propagation of the $\mathrm{t}-\mathrm{m}$ phase transformation. $(9,10)$ When Zirconia core is veneered with dental porcelain (i.e. zirocnia- based restorations), zirconia is not directly exposed to the oral environment or to saliva, thus, the influence of LTD could be limited. However, monolithic zirconia crowns will be directly exposed to saliva. Therefore, it is reasonable to assume that LTD may occur.(11) In addition, mechanical loading and LTD together may reduce the mechanical properties of monolithic zirconia. Therefore the aim of this study was to investigate the effect of thermal cycling and mechanical loading on the flexural strength of a Yttria stabilized (Y- TZP) zirconia. The hypothesis was that aging does not affect the flexural strength of the translucent mono lithic zirconia.

\section{MATERIALS AND METHODS}

The material used in this study was Zeno Star (T) translucent partially sintered Yttria stabilized monolithic zirconia. It is in the form of milling discs for use in the CAD-CAM technique for fabrication of single tooth and multi unit restorations. The composition of the material is presented in table I. 
TABLE (I) Material used and its composition

\begin{tabular}{|c|c|c|c|}
\hline Material & $\begin{array}{c}\text { Commercial } \\
\text { name }\end{array}$ & Composition & Manufacture \\
\hline $\begin{array}{c}\text { Translucent } \\
\text { monolithic } \\
\text { zirconia }\end{array}$ & Zeno star T & $\begin{array}{c}\text { Zirconia oxide } \\
(\mathrm{ZrO}+\mathrm{Hfo}+\end{array}$ & $\begin{array}{c}\text { Wiel and } \\
\text { dental }\end{array}$ \\
& & $\mathrm{Y}_{2} \mathrm{O}_{2} \geq 99 \%$ & Yttrium oxide \\
& & $\begin{array}{c}\text { A company } \\
\text { of Ivoclar } \\
\left.\mathrm{Y}_{2} \mathrm{O}_{2}\right)>4.5-\leq \\
6 \%)\end{array}$ & $\begin{array}{c}\text { Vivadent } \\
\text { group }\end{array}$ \\
& & $\begin{array}{c}\text { Hafnium oxide } \\
\left(\mathrm{Hfo}_{2}\right) \leq 5 \%\end{array}$ & \\
& & $\begin{array}{c}\text { Aluminum oxide } \\
+ \text { other oxide } \leq\end{array}$ & \\
& & $1.0 \%$ & \\
\hline
\end{tabular}

A total number of 40 fully sintered bar shaped specimens $(18 \mathrm{~mm} \times 4 \mathrm{~mm} \times 1.2 \mathrm{~mm})$ were fabricated and sintered at $1450^{\circ} \mathrm{C}$ using the ZenoTec system according to the manufacturer instructions. The specimens were divided into four groups $(n=10)$ according to the aging time:

Group I: is the control group with no aging procedures and was tested after $24 \mathrm{hrs}$.

Group II: subjected to thermal cycling (600 cycles) and load cycling 120,000 cycles equivalent to six months of clinical service.

Group III: subjected to thermocycling (1200 cycles) and load cycling 240,000 cycles, equivalent to one year of clinical service.

Group IV: subjected to thermal cycling 6000 thermal cycles and load cycles of 1,200,000 cycles equivalent to 5 years of clinical service. ${ }^{(12)}$ For thermal cycling, all specimens were transferred in hot and cold water baths between 5 and $55^{\circ} \mathrm{C}$ in one minute cycle for each bath with a dwell time of 30 seconds.

Mechanical loading was performed in a custom made cyclic loading machine. Bar specimens were fixed into copper rings filled with rubber base which were attached to the lower member of the cyclic machine. Human premolars were adjusted as antagonist and fixed to the upper arm of the machine. The functional buccal cusp tip was directed towards the center of the bar. When the motar drive ran, the premolars moved up and down with a uniaxial load of 49 Newtons and a frequency of $2 \mathrm{~Hz}$. Rubber dam sheet was applied between the specimens and the premolars to distribute the force. ${ }^{(13)}$ The flexural strength was determined by three points bending test in a universal testing machine (AGS - X 100 Shimadzu, Japan). The load was applied to the central part of the specimen with a knife edge indenter with a roller span of $16 \mathrm{~mm}$ between the supports at a cross head speed of $1 \mathrm{~mm} / \mathrm{min}$ till fracture. ${ }^{(14)}$ The maximum fracture load in Newtons was recorded and the flexural strength (Fs) in MPa was calculated as follows:

$$
\mathrm{FS}=\frac{3 \mathrm{LD}}{2 w h^{2}}
$$

Where $\quad \mathrm{L}=$ maximum load in Newtons

$\mathrm{D}=$ roller span $(16 \mathrm{~mm})$

$\mathrm{W}=$ Specimen width $(2 \mathrm{~mm})$

$\mathrm{H}=$ Specimen height $(2 \mathrm{~mm})$

Before each measurement, specimen dimensions were measured with a digital caliper with an accuracy of $0.001 \mathrm{~mm}$.

Crystalline phase on the surface of representative specimens was analyzed with $\mathrm{x}$-ray diffraction (XRD).XRD is a versatile, non destructive technique that reveals information about the crystallographic structure of natural and manufactured materials. Specimens were examined before aging and at the end of the aging period which is equivalent to 5 years of clinical service. The crystalline phases were calculated from the reflection of tetragonal zirconia phase at (101 peak) and monoclinic phase at (111 and -111 peak). The relative amount of monoclinic phase was calculated by the method of Gravie and Nicholson ${ }^{(15)}$ which is most commonly applied to determine phase composition of zirconia powders and compacts. 


\section{Statistical analysis}

The data was collected and entered into the personal computer. Statistical analysis was done using statistical package for social sciences (SPSS/ version 21) software. Analysis of variance ANOVAtest was used for parametric data followed by post hoc test to determine the significance between each two groups. The level of significance was set at $0.05 \%$ level. The mean flexural strength values and standard deviations of the four tested groups are presented in table II and in figure I.

The mean flexural strength of zirconia in group II (representing six months of clinical service) was significantly higher $(1563.7 \pm 103.8 \mathrm{MPa})$ than that of group I with no aging procedures $(1009.7 \pm 107.2 \mathrm{MPa}) \quad$ Thermal cycling and mechanical loading equivalent to one year of clinical service (group III) led to a significant decrease in the flexural strength $(1381 \pm 295 \mathrm{MPa})$ compared to group II. The lowest flexural strength was found in group IV $(833.7 \pm 15.2 \mathrm{MPa})$ where zirconia was subjected to thermal cycling and mechanical loading equivalent to 5 years of clinical service.

TABLE (II) Comparison of flexural strength of the four studied groups in $\mathrm{MPa}$.

\begin{tabular}{|l|c|c|c|c|}
\hline & $\begin{array}{c}\text { Group I } \\
\text { (Control } \\
\text { group) }\end{array}$ & $\begin{array}{c}\text { Group } \\
\text { II (6 } \\
\text { months) }\end{array}$ & $\begin{array}{c}\text { Group } \\
\text { III (12 } \\
\text { months) }\end{array}$ & $\begin{array}{c}\text { Group IV } \\
\text { (5 years) }\end{array}$ \\
\hline Range & $\begin{array}{c}938.3- \\
1133.0\end{array}$ & $\begin{array}{c}1465.0- \\
1672.0\end{array}$ & $\begin{array}{c}1090.0- \\
1680.0\end{array}$ & $\begin{array}{c}820.0- \\
850.0\end{array}$ \\
\hline Mean & 1009.7 & 1563.7 & 1381.0 & 833.7 \\
\hline S.D. & 107.2 & 103.8 & 295.1 & 15.2 \\
\hline F & \multicolumn{5}{|c|}{$0.001^{*}$} \\
\hline P & \multicolumn{5}{|c|}{0.52} & $0.001^{*}$ \\
\hline P1 & $0.001^{*}$ & $0.0162^{*}$ & $0.001^{*}$ \\
\hline P2 & \multicolumn{5}{|c|}{$0.001^{*}$} \\
\hline P3 & \multicolumn{5}{|c|}{} \\
\hline \\
P1 comparison between control and other groups. \\
5 years. \\
P3 comparison between 12 months and 5 years.
\end{tabular}

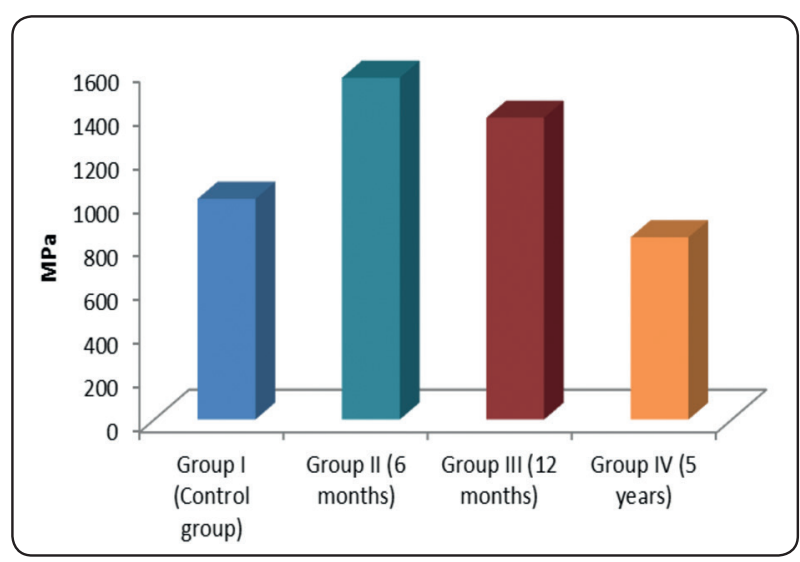

Fig. (1): Showing the flexural strength of Y-TZP at the different aging periods.

The XRD pattern of zirconia specimens are shown in figures (2 and 3). The XRD peak intensity before aging showed a typical tetragonal phase with no monoclinic phase detection. After aging the relative XRD peak intensity revealed that there were some monoclinic transformations.

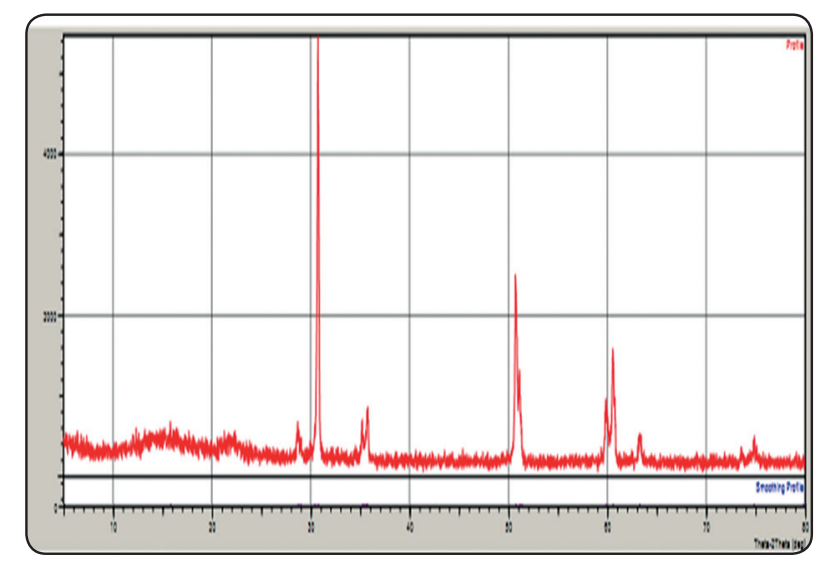

Fig. (2): Showing XRD patterns of Y-TZP before aging with a typical tetragonal phase. 


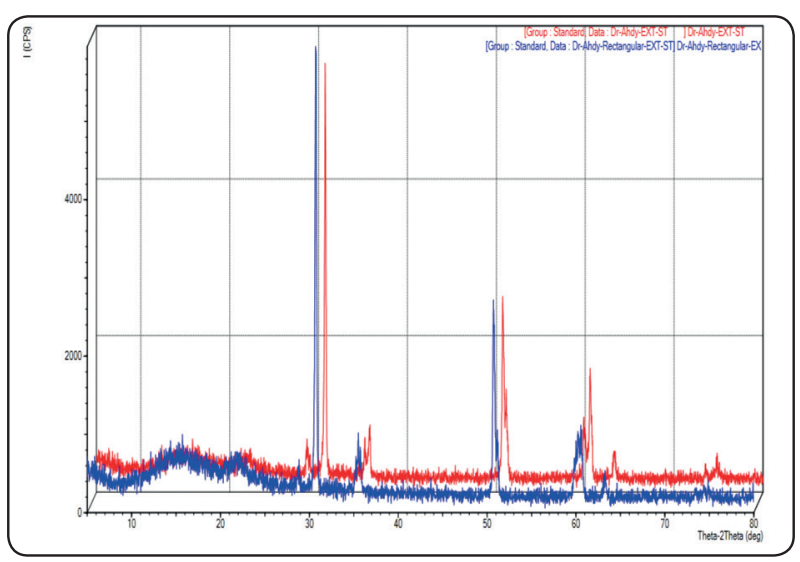

Fig. (3): Showing XRD patterns of Y-TZP at the end of the aging period. The minor peaks labeling monoclinic $\mathrm{ZrO} 2$ at $2 \Theta$.

\section{DISCUSSION}

To overcome the problems caused by chipping of the veneering ceramics, monolithic zirconia has recently been introduced. Translucent Y-TZP ceramics are obtained by decreasing the grain size or by adding doping agents that segregate at the grain boundaries. ${ }^{(16,17)}$

Some translucency was also obtained by decreasing the alumina content which might compromise the ceramic resistance to hydrothermal degradation. ${ }^{(18)}$ Low temperature degradation of zirconia is a negative phenomenon related to the transformation ability of the tetragonal phase. Studies of the aging of zirconia is therefore an important method to assess the changes that occur to the properties of zirconia and thus expecting its life span. It is known that the durability of all ceramic restorations is influenced by repeated exposures to cycles of stress during normal mastication. ${ }^{(19)}$ Thus, thermal cycling in combination to mechanical loading, the (TCML) method is used in this study as it is often performed to predict the durability of ceramic restorations. ${ }^{(20)}$ Furthermore, in case of monolithic zirconia LTD may affect the durability. Mechanical properties such as flexural strength are the first parameters to be assessed to understand the clinical potential and limitations of a dental ceramic. So, the purpose of the present study was to assess the effect of thermal cycling and mechanical loading on the flexural strength of translucent monolithic Y-TZP zirconia after 120.000, 240.000 and 1.200.000 mechanical loading for simulating 6 months, one year and 5 years of clinical service respectively.

The results of this study showed that there was a significant increase in the flexural strength of zirconia subjected to thermal cycling and mechanical loading (equivalent to 6 months of clinical service) compared to the control group which was not subjected to aging. This might be contributed to the increased percent of the monoclinic phase which leads to volume expansion, thus decreasing residual stresses and inhibiting crack growth thus increasing the flexural strength. ${ }^{(21)}$ This finding was in agreement with previous studies of Deville et $\mathrm{al}^{(22)}$ Chevalier et $\mathrm{al}^{(23,34)}$ and Kim et $\mathrm{al}^{(25)}$ who reported that the initial $\mathrm{t}-\mathrm{m}$ transformation is confined superficially and is associated with a net 3-4\% volume expansion due to the larger volume occupied by the monoclinic phase compared to the tetragonal, which causes closure of any surface microcracks restricting them to propagate into the bulk of the material. This unique transformation toughening may explain the initial increased flexural strength which occurred in the current study. In the current research a significant decrease in the flexural strength was reported following 6000 thermal cycling and 1.200.000 mechanical loading which is equivalent to 5 years of clinical service. This finding was in consistence with Siarampi et $\mathrm{al}^{(26)}$, Cotes et $\mathrm{al}^{(27)}$ and with previous studies of Swab ${ }^{(28)}$ and Cattani-Lorente. ${ }^{(29)}$ They all reported that when saturation occurs at the surface of zirconia in the monoclinic phase, transformation occurs in the bulk under the influence of occlusal loads in the oral environment. Monoclinic phase transformation flaws act as stress concentration sites for microcracks initiation and propagation inside the bulk of ceramics, thus enhancing the 
LTD process facilitating water penetration. In this situation internal cracks occur in the critical zone and cause reduction in the flexural strength.

Chevalier et $\mathrm{al}^{(24)}$ also explained that large shear strain and displacements accompanying the transformations can also create cracks along the grain boundaries that in turn allow moisture to penetrate further into the material and the process is repeated as moisture ingress continues.

Three different rationales have been suggested in the literature leading to LTD. The first hypothesis is that water interacts with yttrium generating yttrium hydroxide which affects the stabilizer causing yttrium deficiency and transformation of tetragonal to monoclinic phase. Another mechanism suggested that water breaks the bond between $\mathrm{Zr}$ and $\mathrm{O}_{2}$, resulting in localized stress growth due to $-\mathrm{OH}$ movement inside the crystal structure. This motion causes lattice fault that acts as nucleating agent for crystalline changes. The last theory is that $\mathrm{O}_{2}$ from water break down fills oxygen vacancies. ${ }^{(30)}$ However, the mean flexural strength values observed in this study (833.7 MPa) after 5 year of clinical simulation were higher than other commercially available ceramic materials. The results of the present study was in disagreement with Curtis et $\mathrm{al}^{(31)}$ and Pittayachawan et $\mathrm{al}^{(32)}$ who reported that the flexural strength of Y-TZP was not significantly changed after aging. $\operatorname{Ardlin}^{(33)}$ and Papangiotou et al ${ }^{(34)}$ also did not find any significant reduction in the strength of zirconia after hydrothermal and mechanical loading which was not in consistence with the results of the present study. They suggested that the $\mathrm{t}-\mathrm{m}$ transformation zone did not extend deep enough into the ceramics. The increase of monoclinic phase induced by aging of Y-TZP is documented in the literature. ${ }^{(35)}$ The XRD analysis in the present study showed some amounts of $t-m$ transformation at the end of the aging period which is equivalent to five years of clinical service. This was in agreement with the results of Cotes at $\mathrm{al}^{(27)}$ who found insignificant percentage of monoclinic phase after mechanical cycling. While Pittayachawan $^{(32)}$ did not find monoclinic phase in mechanically loaded specimens. This might be related to the different chemistry of zirconia substrate used in their investigations, as not all the Y-TZP brands are the same in terms of their composition mainly Yttria and aluminum oxide content and the grain size also may affect their microstructure and resistance to LTD. ${ }^{(36,37)}$ The smaller the grain size in monolithic zirconia, the less the transformation to the monoclinic phase and thus suppressing hydrothermal degradation. ${ }^{(38)}$ The phase transformation, even in small amounts may be attributed to subcritical crack growth behavior of Y-TZP under cyclic loading.

\section{CONCLUSIONS}

Within the limitations of this study the following conclusions can be drawn.

1. The flexural strength of translucent monolithic Yttria stabilized zirconia is decreased after thermal cycling and mechanical loading at the period equivalent to one year of clinical service.

2. Further decrease of flexural strength occurred following aging at the period simulating five years of clinical service.

3. At the end of the aging period there were some induced monoclinic transformation which provides evidence of the instability of the tetragonal phase.

\section{REFERENCES}

1. Guazzato M, Albakry M, Ringer S, Swain M. Strength, fracture toughness and microstructure of a selection of all ceramic materials Part II. Zirconia - based dental ceramics. Dent Mater 2004; 20(5): 449-456.

2. Zhang Y, Lee JJ, Srikanth R, Lawn BR. Edge chipping and flexural resistance of monolithic ceramics. Dent Mater 2013; 29: 1201-8

3. Zhang Y. Making Yttria - stabilized tetragonal zirconia translucent. Dent Mater 2014; 30: 1195-203. 
4. Deville G, Chevallier J. Martensitic transformation in zirconia: Part I. Nanometer scale prediction and measurement of transformation induced relief Sylvain. Acta Mater 2004; 52: 5697-707.

5. Chevalier J, Gremillard L, Virkar AV, Clarke DR. The tetragonal-monoclinic transformation in zirconia: lesson learned and future trends. J Am Ceram Soc 2009;92:190120.

6. Roy ME, Whiteside LA, Katerberg BJ, Steiger JA. Phase transformation, roughness and microhardness of artificially aged Yttria and magnesia stabilized zirconia femoral heads. J Biomed Mater Res 2007; 83: 1096-102.

7. Borchers L, Stiesch M, Bach FW, Buhl JC, Hubsch C, Kellner T. Influence of hydrothermal and mechanical conditions on the strength of zirconia. Acta Biomater 2010; 6: 4547-52.

8. Itinoche KM, Ozcan M, Bottino MA, Oyafuso D. Effect of mechanical cycling on the flexural strength of densely sintered ceramics. Dent Mater 2006; 22: 1029-34.

9. Nakamura K, Harada A, Kanno T, Inagaki R, Niwano Y, Milleding P. The influence of low temperature degradation and cyclic loading on the fracture resistance of monolithic zirconia molar crowns. J Mech Behav Biomed Mater 2015; 47: 49-56.

10. Nakamura K, Harada A, Ono M, Shibasaki H, Kanno T, Niwano Y. Effect of low temperature degradation of the mechanical and microstructural properties of tooth-coloured 3Y-TZP ceramics. J Mech Behav Biomed Mater 2016; 53: 301-11.

11. Cattani - Lorente M, Durual S, Amez-Droz M, Anselm Wiskott HW, Scherrer S. Hydrothermal degradation of a 3Y-TZP translucent dental ceramic: A comparison of numerical predictions with experimental data after two years of aging. Dent Mater 2016; 32: 394-402.

12. Rosentritt M, Behr M, Zel J, Feilzer A. Approach for valuating the influence of laboratory simulation. Dent Mater 2009;25:348-352.

13. Hosseini MI, Kleven E, Gotfredsen K. Fracture mode during cycling loading of implant - supported single tooth restorations. J Prosthet Dent 2012; 108(2): 74-83.

14. Cho HY, Wone HY, Choeb HC, Sonc MK. Fracture characteristics of dental ceramic crown according to zirconia coping design. Proc Eng 2011; 10: 1561-1566.

15. Gravie RC, Nicholson PS. Phase analysis in zirconia systems. J Am Ceram Soc 1972;55:303-45.
16. Xiong Y, Fuz Y, Pouchly V, Macak, Shen ZJ. Preparation of transparent 3 Y-TZP nanoceramics with no low temperature degradation. J Am Ceram Soc 2014; 97: 1402-6.

17. Zhang F, Vanmeensel K, Batuk M, Hadermann J, Inokoshi M, Van Meerbeek B. Highly translucent strong and aging resistant 3 Y-TZP ceramics for dental restorations by grain boundary segregation Acta Biomater 2015; 16: 215-22.

18. Zhang F, Inokoshi M, Van meensel K, Van Meerbeek B, Naert I, Vleugels J. Life time estimation of zirconia ceramics by linear aging kinetics. Acta Mater 2015; 92: 290-8.

19. Anusavice, K.J. Dental ceramics. In: Phillips science of dental materials. K.J. Anusavice, C. Shen and H.R. Rawls editors. St. Louis, Mo, USA: Saunders. 2013 pp. 418-473.

20. Altia, A., Kern, M. Influence of cycling loading and luting agents on the fracture load of two all ceramic crown systems. J. Prosthet Dent 2004 92: 551-556.

21. Hannink RHJ, Kelly PM, Muddle BC. Transformation toughening in zirconia-containing ceramics. J Am Ceram Soc 2000; 83: 461-87.

22. Deville, S., Gremillard L . Chevalier, J., Fantozzi, G. A critical comparison of methods for the determination of the aging sensitivity in biomedical grade yttria-stabilized zirconia . J.Biomed.Mater. Res Appl Biomater 2005;72B: 239-245.

23. Chevalier, J.,Gremillard L., Deville, S. Low temperature degradation of zirconia and implications for biomedical implants. Annu Rev Mater Res 2007; 37: 1-32.

24. Chevalier J.,Gremillard , L., Virkar, A.V., Clarke, D.R. The tetragonal - monoclinic transformation in zirconia: lessons learned and future trends. J. Am Ceram Soc 2009; 92: 1901-1920.

25. Kim, H.T, Han, J.S, Yang, J.H, Lee, J.B, Kim, S.H. The effect of low temperature aging on the mechanical property and phase stability of Y-TZP ceramics. J. Adv. Prosthodont 2009; 1: 113-117.

26. Siarampi E, Kontonasaki E, Papadopoulou L, Kantiranis N, Zorba T, Paraskevopoulos KM. Flexural strength and probability of failure of cold isostatic pressed zirconia core ceramics for ceramic restorations. J Prosthet Dent 2012;108:84-95.

27. Cotes, C., Arata A, Melo, R.M, Bottino, M.A Machado, J.P., Souza RO. Effects of aging procedures on the topographic surface, structural stability and mechanical strength of a ZrO-based dental ceramic. Dent Mater 2014; 30: 396-404. 
28. Swabb JJ. Low temperature degradation of a Y-TZP materials. J Mater Sci 1991; 26: 6706-14.

29. Cattani - Lorente M, Scherrer SS, Ammann P, Jobin M, Wiskott HW. Low temperature degradation of a Y-TZP dental ceramic. Acta Biomater 2011; 7: 858-65.

30. Alghazzawi TF, Lemons J, Liu PR, Essig ME, Barto Lucci AA, Janowski GM. Influence of low-temperature environmental exposure on the mechanical properties and structural stability of dental zirconia. Journal of Prosthodontics 2012; 21 no 5 363-369.

31. Curtis AR, Wright AJ, Fleming GJP. The influence of simulated masticatory loading regimes on the biaxial flexure strength and reliability of a Y-TZP dental ceramic. J Dentist 2006;34:317.

32. Pittayachawan P, McDonald A, Petrie A, Knowles JC. The biaxial flexural strength and fatigue property of Lava YTZP dental ceramic. Dent Mater 2007; 23: 1018-29.

33. Ardlin BI. Transformation-toughened zirconia for dental inlays, crowns and bridges: chemical stability and effect of low temperature aging on flexural strength and surface structure. Dent Mater 2002; 18: 590-5.
34. Papanagiotou HP, Morgano SM, Giordano RA, Poer R. In vitro evaluation of low temperature aging effect and finishing procedures on the flexural strength and structure stability of Y-TZP dental ceramics. J Prosthet Dent 2006;96:154-64.

35. Brian D. Flinn, Ariel J, Raigrodski DMD, Lloyd A, Mancl, Ryan Toivola, Tuesday kuykendall. Influence of aging on the flexural strength of translucent zirconia for monolithic restorations. J Prosthet Dent 2017;117:303-309.

36. Pereira GKR, Venturini AB, Silvestri T, Dapieve KS, Montagner AF, Soares FZM, Valandro LF. Low temperature degradation of Y-TZP ceramics, a systemic review and meta - analysis. J Mech Behav Biomed Mater 2015;55:151-163.

37. Zhang F, Vanmeensel K, Inokoshi M, Batuk M, Hadermann J, Van Meerbeek B, Naert I, Vleugels J. Critical influence of alumina content on the low temperature degradation of 2-3 mol\% yttria - stabilized TZP for dental restorations. J Eur ceram Soc 2015;35:741-750.

38. Flinn BD, Raigrodski AJ, Singh A, Mancl LA. Effect of hydrothermal degradation on three types of zirconia for dental application. J Prosthet Dent 2014;112:1377-1384 . 